\title{
Hypophosphataemia and phosphorus requirements during intravenous nutrition
}

\author{
S. J. TOVEY* \\ M.B., B.S. \\ K. G. F. Benton $\dagger$ \\ M.B., B.S. \\ H. A. LEE $\ddagger$ \\ B.Sc., M.B., B.S., F.R.C.P. \\ *Chemical Pathology Department, Bristol Royal Infirmary, Bristol BS2 $8 \mathrm{HW}$, \\ †Wessex Regional Renal Unit, St Mary's Hospital, Portsmouth, and \\ $\ddagger$ Department of Nephrology, University of Southampton, and Wessex Regional Renal Unit, Portsmouth
}

\begin{abstract}
Summary
Seven patients with acute illnesses developed hypophosphataemia whilst receiving intravenous nutrition which included a fat emulsion, Intralipid, a possible source of phosphorus. The authors' observations cast doubt on the bio-availability of the phosphorus contained in the phospholipid content of the fat emulsion. The currently recommended allowance of phosphorus for this type of patient appears to be too low and it is suggested that $0.5-0.75 \mathrm{mmol} / \mathrm{kg}$ bodyweight be provided, preferably as a neutral phosphate solution. Since hypophosphataemia can occur at various time intervals after starting intravenous nutrition and precede clinical sequelae it is recommended that routine serum phosphate measurements are made in all patients receiving this treatment.
\end{abstract}

\section{Introduction}

Hypophosphataemia complicating total intravenous nutrition has previously been observed (Travis et al., 1971; Silvis and Paragas, 1972; Woods and Alberti, 1972; Prins, Schrijner and Staghouwer, 1973; Betro and Pain, 1972; Sheldon and Gryzb, 1975). Most of the patients reported who developed hypophosphataemia were receiving intravenous nutritional regimes obviously deficient in phosphorus. The daily recommended requirement of phosphorus for adults is $0.15 \mathrm{mmol} / \mathrm{kg}$ bodyweight and for infants, between 0.4 and $0.8 \mathrm{mmol} / \mathrm{kg}$ (Recommended Dietary Allowances, 1968). With the increasing application of complete parenteral nutrition to critically ill patients, it becomes increasingly important to be aware of possible complications. Often intravenous nutritional regimes appear to provide all the necessary elements and yet still the deficiencies may occur. This raises the questions as to whether such measurements represent true deficiencies or an induced redistribution. If a redistribution-does this require any correction, and if so, when and by what means?

Reprint requests: Professor H. A. Lee, St Mary's Hospital, Portsmouth.
A series is now reported of patients in whom hypophosphataemia complicated intravenous nutritional regimes although the phosphorus intake exceeded $0.15 \mathrm{mmol} / \mathrm{kg} /$ day. The importance of hypophosphataemia is particularly related to its effect on the red cell affinity for oxygen where it causes a displacement of the oxygen dissociation curve to the left. This means that, in critically ill patients where there may already be a tendency for peripheral anaerobic glycolysis, hypophosphataemia will accentuate this by depletion of red cell 2,3diphosphoglycerate (2,3-DPG). The relationship of phosphorus depletion to oxygen transport has recently been reviewed by Sheldon and Gryzb (1975).

\section{Case reports}

Case 1

A 19-year-old female, weight $65 \mathrm{~kg}$, with a 2-year history of Crohn's disease was admitted in oligaemic shock following 2 weeks of profuse diarrhoea. On admission her blood urea was $100 \mathrm{mmol} / 1$. Treatment with intravenous dextrose and saline, gentamicin and frusemide was given but her urine output fell below $200 \mathrm{ml} /$ day. On the fourth day of admission a leg shunt for haemodialysis was inserted and intravenous nutrition (amino acids (Vamin-Glucose), Intralipid and glucose-insulin) via a subclavian vein begun. Although $10 \mathrm{mmol}$ of phosphorus per day were provided from Intralipid, hypophosphataemia occurred 4 days later (Fig. 1). A chest $\mathrm{X}$-ray showed right middle lobe pneumonia. Blood gases whilst breathing air gave an arterial blood pH of 7.5 and $\mathrm{a} \mathrm{Po}_{2}$ of $7 \mathrm{kPa}(50 \mathrm{mmHg})$. A neutral phosphate solution $\left(0 \cdot 1 \mathrm{~mol} / 1 \mathrm{KH}_{2} \mathrm{PO}_{4} . . \mathrm{Na}_{2} \mathrm{HPO}_{4}\right)$ providing $35 \mathrm{mmol}$ of phosphorus was infused and the serum inorganic phosphate rose to $0.84 \mathrm{mmol} / 1$. However, $24 \mathrm{hr}$ later (day 10) hypophosphataemia $0.45 \mathrm{mmol} / 1$ recurred. Hypokalaemia was not associated with hypophosphataemia in this patient. A further $75 \mathrm{mmol}$ of phosphorus were given as neutral phosphate solution over the next $48 \mathrm{hr}$, 

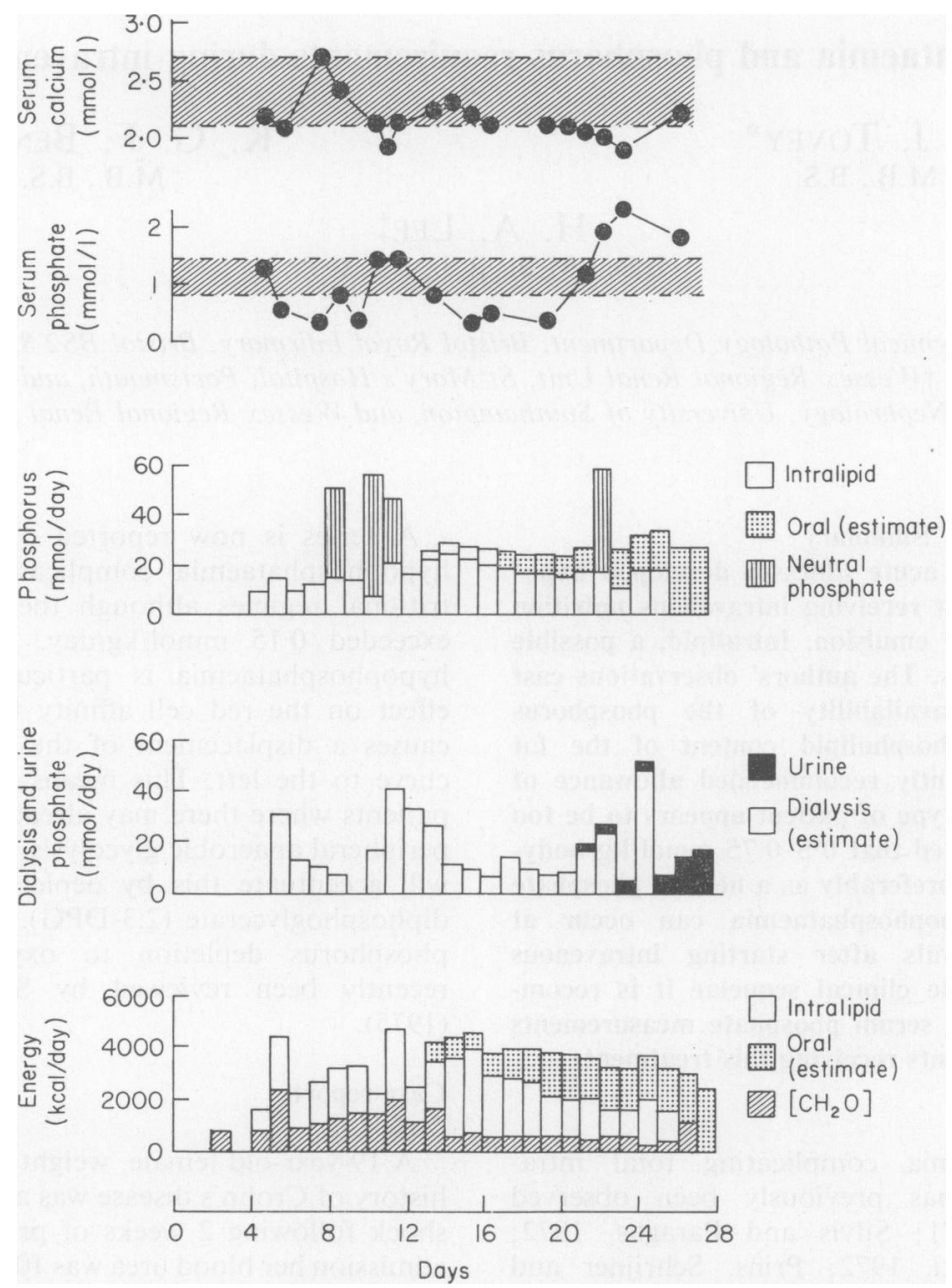

Fig. 1. Case 1, female aged 19 years. Hypophosphataemia occurred when there were no urinary losses, haemodialysis losses were appreciable, and complete intravenous nutrition begun. On both occasions hypophosphataemia was corrected by neutral phosphate infusions.

during which time calcium gluconate had to be given to control carpo-pedal spasm (serum calcium 1.95 and magnesium $1.0 \mathrm{mmol} / \mathrm{l}$ ). Insulin was added to the i.v. regime from day 9 to 12 to control hyperglycaemia. Hypophosphataemia recurred on day 16 even though more than $15 \mathrm{mmol}$ of phosphorus were being given per day as Intralipid phospholipid. On day 22 a further $40 \mathrm{mmol}$ of phosphorus as neutral phosphate solution was infused, when the serum phosphate rose to within the normal range. Thereafter there was a steady improvement in general condition and the patient was discharged on day 41 .

\section{Case 2}

A previously healthy female aged 34 years, weight
$55 \mathrm{~kg}$, developed intestinal ileus and pyrexia $\left(41^{\circ} \mathrm{C}\right)$ after ovarian cystectomy and a cholecystectomy for chronic cholecystitis with cholelithiasis. On the fifth postoperative day she was oliguric, collapsed and uraemic. Treatment with intravenous fluid, electrolyte replacement and intravenous nutrition (amino acids (Vamin-Glucose), Intralipid and glucoseinsulin) was begun. Two days later even with a phosphorus intake of $18.5 \mathrm{mmol} /$ day derived from Intralipid phospholipids the serum inorganic phosphate fell to $0.74 \mathrm{mmol} / \mathrm{l}$ (Fig. 2). Forty-eight hours later when the mean phosphorus provision from Intralipid phospholipid was $26.5 \mathrm{mmol} / \mathrm{day}$ the serum inorganic phosphate fell to $0.32 \mathrm{mmol} / \mathrm{l}$. Insulin, 20-160 u./day, was added to the i.v. regime 

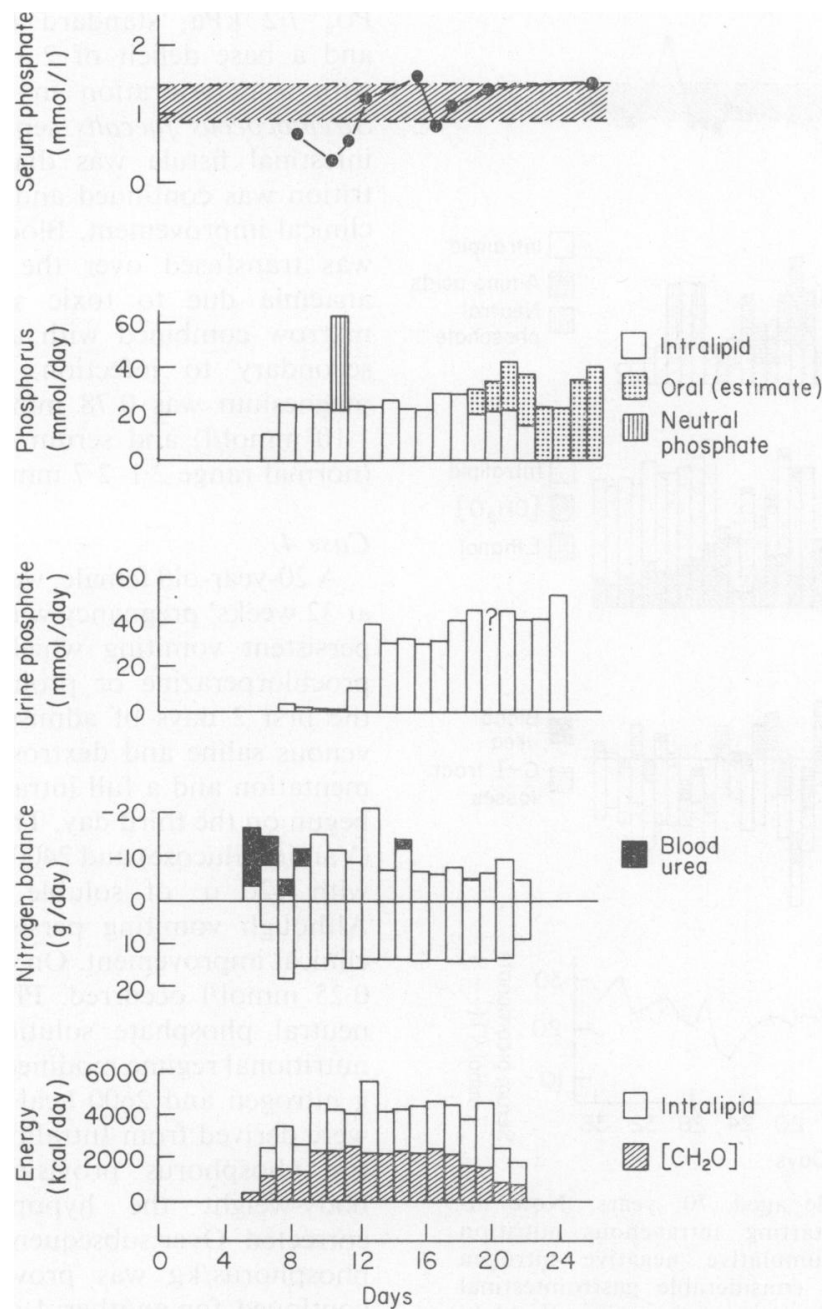

FIG. 2. Case 2, female aged 34 years. Hypophosphataemia developed without concurrent phosphaturia, but was related to onset of intravenous nutrition. It was rapidly corrected by neutral phosphate infusion. Blood urea correction for nitrogen balance according to Lee and Hartley (1975) formula. Nitrogen balance improved with additional nitrogen provision after day 21 .

for control of hyperglycaemia. Marked respiratory insufficiency occurred owing to bilateral bronchopneumonic change and even with $40 \%$ added oxygen the arterial $\mathrm{Po}_{2}$ was $6.5 \mathrm{kPa}$. With intermittent positive pressure ventilation the arterial $\mathrm{pH}$ was $7 \cdot 55$. Following $40 \mathrm{mmol}$ of phosphorus intravenously as neutral phosphate solution the serum inorganic phosphate rose to $1.2 \mathrm{mmol} / \mathrm{l}$ (day 12). From day 6 to 21 the mean insulin requirement was $100 \mathrm{u}$./day to maintain normoglycaemia. On day 15 a further laparotomy disclosed an acute pancreatitis. Following this operation there was a further slight fall in serum inorganic phosphate but the patient continued to improve and with the recommencement of normal oral nutrition her serum inorganic phosphate returned to the upper limits of normal. When discharged home on the thirty-third day she was $2 \mathrm{~kg}$ above her pre-operative weight.

\section{Case 3}

A 70-year-old female, weight $66 \mathrm{~kg}$, with a history of diverticulitis, was admitted with a 5-day history of recurrent lower abdominal pain accompanied by vomiting and diarrhoea. An exacerbation of diverticular disease was diagnosed and her subsequent metabolic progress is shown in Fig. 3. Laparotomy 5 


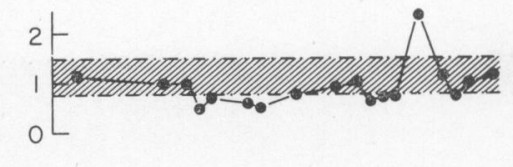

高旁高
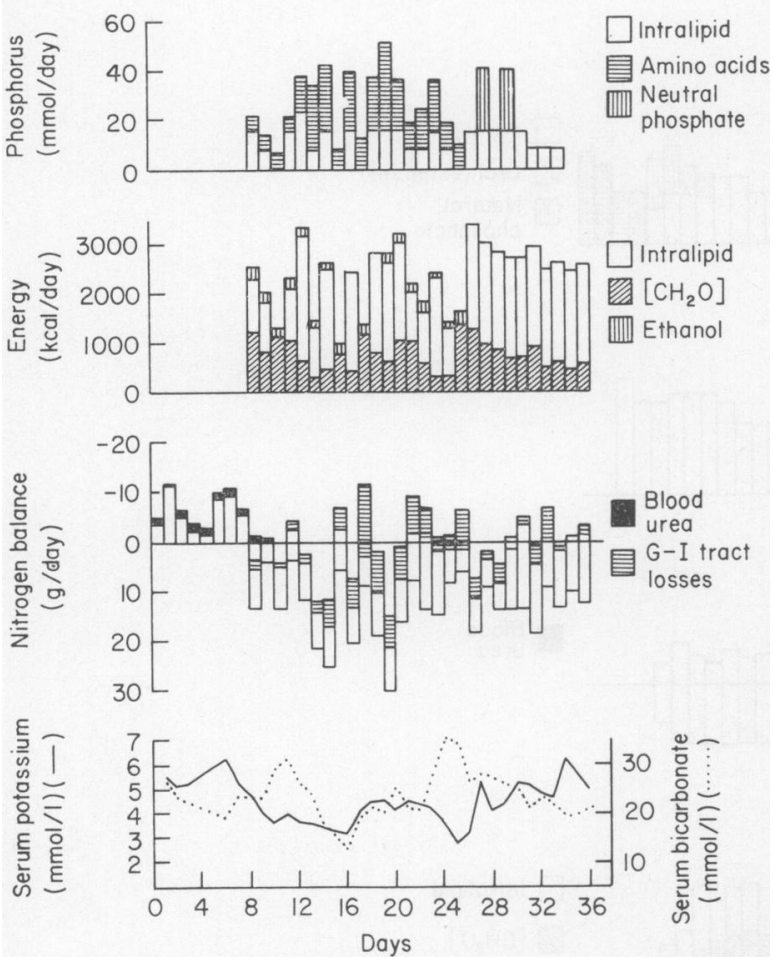

Fig. 3. Case 3, female aged 70 years. Note inappropriate delay in starting intravenous nutrition allowing appreciable cumulative negative nitrogen balance to occur. Note considerable gastrointestinal tract losses of nitrogen, measured by micro-Kjeldahl method. From days 8 to 26 amino acid solutions used were aminosol $10 \%$ and amino-fructose-ethanol. Thereafter Vamin-Glucose was used. On two widely separated occasions hypokalaemia, hypophosphataemia and alkalosis were associated. Blood urea correction for nitrogen balance as in Fig. 2 .

days after admission revealed an infarcted right colon with small bowel infarction involving all but 35 $\mathrm{cm}$ of the jejunum. Resection of most of the small bowel together with a right hemi-colectomy was undertaken. Septicaemia occurred 2 days postoperatively and a complete intravenous nutrition regime was begun $24 \mathrm{hr}$ later. Hypophosphataemia occurred on days 11 and 26 with associated hypokalaemic metabolic alkalosis. On day 22 the patient developed orthopnoea and generalized oedema which responded to intravenous frusemide. The following day she was found to have a hypokalaemic metabolic alkalosis, arterial pH 7.53, $\mathrm{PCO}_{2} 3 \cdot 2 \mathrm{kPa}$,
$\mathrm{Po}_{2} 7 \cdot 2 \mathrm{kPa}$, standard bicarbonate $22.2 \mathrm{mmol} / \mathrm{l}$ and a base deficit of $2.3 \mathrm{mmol} / \mathrm{l}$. Two days later with a deterioration in her general condition a Streptococcus faecalis septicaemia complicating an intestinal fistula was diagnosed. Intravenous nutrition was continued and resulted in a generalized clinical improvement. Blood, total five units (pints), was transfused over the next 3 days to correct anaemia due to toxic suppression of the bone marrow combined with an episode of haemolysis secondary to infection. On day 31 her serum magnesium was $0.78 \mathrm{mmol} / 1$ (normal range 0.65 $1.10 \mathrm{mmol} / \mathrm{l}$ ) and serum calcium was $2.26 \mathrm{mmol} / \mathrm{l}$ (normal range $2 \cdot 1-2 \cdot 7 \mathrm{mmol} / \mathrm{l}$ ).

\section{Case 4}

A 20 -year-old female, weight $62.5 \mathrm{~kg}$, was admitted at 32 weeks' pregnancy with a 3-day history of severe persistent vomiting which had not responded to prochlorperazine or promethazine theoclate. Over the first 2 days of admission she was given intravenous saline and dextrose with potassium supplementation and a full intravenous nutritional regime begun on the third day. This provided $9.4 \mathrm{~g}$ nitrogen (Vamin-Glucose) and $2400 \mathrm{kcal}$ daily as $50 \%$ glucose with 120 u. of soluble insulin added per litre. Although vomiting persisted there was a general clinical improvement. On day 4 hypophosphataemia $0.25 \mathrm{mmol} / 1$ occurred. Phosphorus $50 \mathrm{mmol}$, as a neutral phosphate solution was infused and the nutritional regime modified to provide a total of $14 \cdot 1$ g nitrogen and $2600 \mathrm{kcal}$ daily of which $2000 \mathrm{kcal}$ were derived from Intralipid. Even on the day when the phosphorus provision exceeded $1 \mathrm{mmol} / \mathrm{kg}$ body-weight the hypophosphataemia was not corrected. Over subsequent days when $0 \cdot 24 \mathrm{mmol}$ of phosphorus/kg was provided hypophosphataemia continued for another 4 days. This patient's hypophosphataemia was not associated with hypokalaemia or alkalosis. On day 7 the patient developed haematemesis and melaena complicated by a severe urinary tract infection. The latter was treated with antibiotics and an emergency oesophagoscopy revealed extensive oesophageal ulceration and bleeding due to an hiatus hernia. On day 8 a live female infant weighing $2.26 \mathrm{~kg}$ was delivered by Caesarian section. On the second postoperative day the patient developed hypernatraemia, hyperchloraemia and hypokalaemia which were corrected by 61 of intravenous $5 \%$ dextrose and $200 \mathrm{mmol}$ of potassium chloride.

\section{Case 5}

A 28 -year-old female, weight $47 \cdot 8 \mathrm{~kg}$, was admitted with a 6-week history of vaginal bleeding. Examination revealed an exophytic tumour of the cervix invading the anterior vaginal vault and the uterine 
endometrium. There was no evidence of metastases. Radium was applied and 9 and 10 days later irradiation of $6000 \mathrm{rad}$ was given to the pelvis. Four months later her condition was good, weight $50.4 \mathrm{~kg}$, but examination revealed a raised edge of a cervical ulcer. Another 6 weeks later she underwent a radical hysterectomy but 2 months afterwards she had developed large vesico-vaginal and rectovaginal fistulae with continual vaginal leakage. After 10 days, this emaciated, depressed and anorexic patient weighed $34 \mathrm{~kg}$. A full intravenous nutritional programme was begun providing 2625 $\mathrm{kcal}$ (975 as glucose and 1650 as fat emulsion) and $14.1 \mathrm{~g}$ of nitrogen (Vamin-Glucose). All elements, trace elements and vitamins were provided inclusive of phosphorus $0.66 \mathrm{mmol} / \mathrm{kg}$ body-weight derived from Intralipid phospholipid. Her condition steadily improved on this regime and within 4 weeks she weighed $39.5 \mathrm{~kg}$. This patient developed marked hypophosphataemia on the second day of intravenous nutrition in spite of provision of apparently adequate amounts of phosphorus. A further slight tendency towards hypophosphataemia occurred on the fifteenth day of intravenous nutrition when the patient had an intercurrent infection.

\section{Case 6}

A 13-month-old male infant, weight $7 \cdot 4 \mathrm{~kg}$, was admitted with a 1-month history of general malaise and 7 days' diarrhoea. A feeding history suggested a diagnosis of rumination. Three days after admission his condition deteriorated and he developed septicaemia secondary to urinary tract infection. He responded to vigorous therapy with intravenous fluids and antibiotics. Subsequent progress was hampered by persistent rumination. Intravenous feeding via a femoral vein was then started providing $438 \mathrm{mg}$ of nitrogen and $120 \mathrm{kcal} / \mathrm{kg}$ body-weight daily. The phosphorus provision in this regime was derived from Intralipid phospholipids yielding 0.4 $\mathrm{mmol} / \mathrm{kg}$. Hypophosphataemia occurred on the fifth day of this regime. After 9 days of intravenous feeding he developed a septicaemia from the i.v. feeding catheter which was then removed.

\section{Case 7}

A 42-year-old male, weight $72 \mathrm{~kg}$, was transferred to this hospital with oliguric renal failure. Thirty-two days earlier he had had an ante-colic Polya reconstruction for pre-pyloric ulceration. Previously there had been a left nephrectomy for hypernephroma, but no evidence of metastases had been found. A small bowel fistula developed 4 days after operation. Parenteral nutrition was begun on the seventh postoperative day and continued over the next 12 days until transferred, providing $0 \cdot 15 \mathrm{~g}$ nitrogen and $17 \cdot 6$ $\mathrm{kcal} / \mathrm{kg}$ body-weight daily. Phosphorus provision over this time derived from Intralipid phospholipid and phosphorus contained in casein hydrolysate (Aminosol $10 \%$ ) amounted to $0.14 \mathrm{mmol} / \mathrm{kg}$. Serum phosphate was not checked during this period. Hydration was good throughout but on day 15 he became jaundiced and the blood urea was elevated. Closure of the fistula by local sutures failed, and formal closure was undertaken on day 31 . Oliguria had been noticed over the previous 2 days and during the operation a short cardiac arrest occurred. Assisted ventilation was required during the next $24 \mathrm{hr}$. The patient remained anuric and was transferred on day 32 for haemodialysis. He was now seriously ill, pyrexial, deeply jaundiced and grossly fluid overloaded. Cardiac output and peripheral perfusion were good with adequate spontaneous respiration. The anterior abdominal wall wound was gaping and bile was draining via a drain in the superior subphrenic space. Blood-stained fluid was still draining from the fistula area. On arrival, the blood urea was $33.7 \mathrm{mmol} / 1$ with a serum phosphate of $2.14 \mathrm{mmol} / 1$. He was immediately haemodialysed and started on a complete intravenous nutrition regime which included albumin and human plasma protein fraction. At this time the amino acid solution used was Vamin-Glucose and provided $0.15 \mathrm{~g}$ nitrogen and $53 \mathrm{kcal} / \mathrm{kg}$. Although Intralipid phospholipids provided a phosphorus intake of $0 \cdot 12$ $\mathrm{mmol} / \mathrm{kg}$, hypophosphataemia occurred after 3 days. The phosphorus intake was increased by the addition of neutral phosphate solution to $0.49 \mathrm{mmol} / \mathrm{kg}$ but severe hypophosphataemia $(0.14-0.18 \mathrm{mmol} / \mathrm{l}) \mathrm{re}-$ curred. The patient died on day 40 from intraabdominal sepsis and associated septicaemia.

TABLE 1. Phosphorus content of UK intravenous nutrition solutions

\begin{tabular}{lr}
\hline Source & $\begin{array}{r}\text { Content } \\
(\mathrm{mmol} / \mathrm{l})\end{array}$ \\
\hline Aminosol 10\% & 15 \\
Aminosol-glucose & 6 \\
Aminosol-fructose-ethanol & 6 \\
Travasol (Baxter) & 15 \\
Freamine II (McGaw) & 20 \\
Intralipid 10\% and 20\% (KabiVitrum) & 15 \\
Neutral phosphate solution (Boots)* & 100 \\
\hline \multicolumn{2}{c}{ * Provided as 500 ml Polyfusor packs which } \\
contain in addition to phosphorus, 162 mmol \\
sodium/1 and 19 mmol/1 potassium.
\end{tabular}

\section{Discussion}

Hypophosphataemia is associated with a decrease in the erythrocyte glucose 6-phosphate, fructose 6-phosphate, 3-phosphoglyceric acid, 2-phosphoglyceric acid, phosphoenolpyruvate, 2,3-DPG and adenosine triphosphate (ATP) with an increase in total triophosphates (Travis et al., 1971). This 
S. J. Tovey, K. G. F. Benton and H. A. Lee

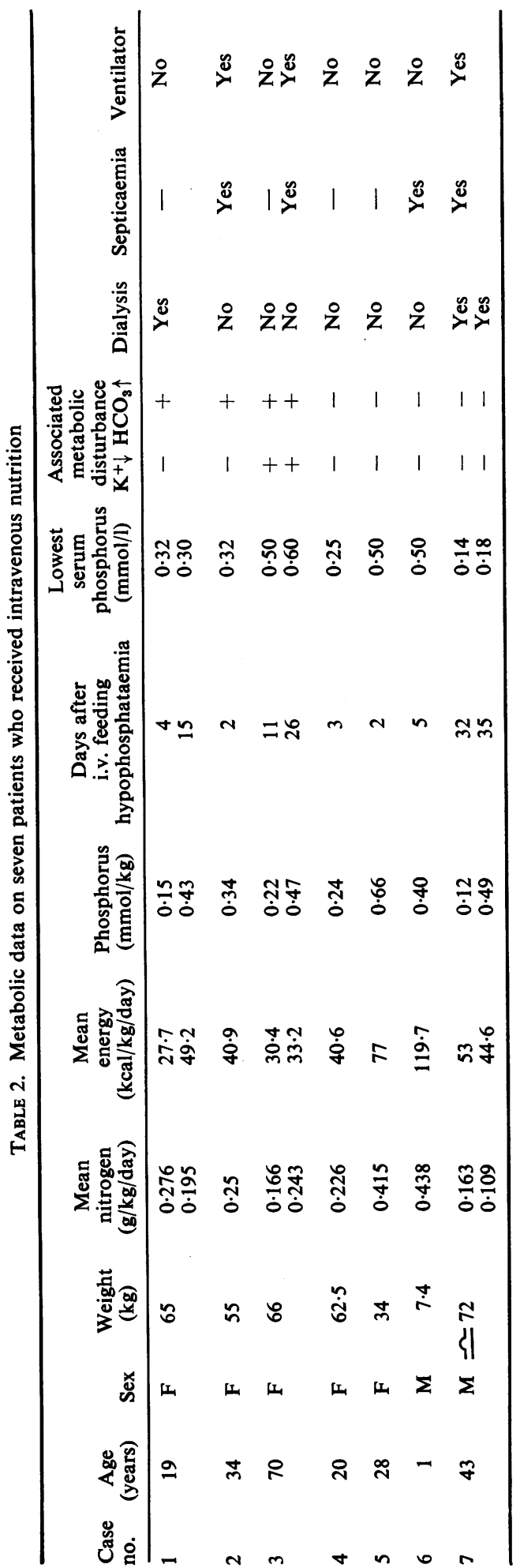


altered metabolic environment of the erythrocyte is associated with a displacement of the oxygen dissociation curve to the left, i.e. an increased affinity of red cells for oxygen and consequent impairment of tissue oxygenation (Sheldon and Gryzb, 1975). This may be of particular significance in critically ill patients with compromised pulmonary function and a low arterial oxygen tension, especially if there is an associated alkalosis. Impairment of tissue oxygenation is thought to be the cause of the central nervous system symptoms associated with hypophosphataemia (Prins et al., 1973; Ricour, Millot \& Balsan, 1975), although the time course of the symptoms does not strictly correlate with the rate of serum phosphate depletion or the duration of intravenous nutrition.

It is generally agreed that phosphorus must be given as an integral part of total parenteral nutrition and meet the minimal requirements quoted. It has been shown in the rat that when inorganic phosphorus and ATP depletion of the liver is induced by fructose infusion, incorporation of leucine into liver protein synthesis is less than $10 \%$ of normal (Maenpaa, Rairo and Kekomaki, 1968). This suggests that phosphate depletion may have even more widespread implications, e.g. enzyme production and consequently impaired immunocompetence. In support of this, acquired phagocyte dysfunction has been reported as a complication of hypophosphataemia in man (Craddock et al., 1974) and the treatment of hypophosphataemia which develops during septicaemia in guinea-pigs results in an improved survival (Garner, Huebner and O'Dell, 1967). Riedler and Scheitlin (1969) concluded Gramnegative septicaemia to be a common cause of hypophosphataemia and such a septicaemia was a feature in four of the present cases (Nos 2, 3, 6 and 7). In other patients with septicaemia more recently observed, however, Tovey (1976, unpublished observations) noted that hypophosphataemia preceded all clinical signs of septicaemia and suggests that prophylactic replacement therapy with phosphate solution may be of importance for prevention or management of septicaemia in man.

There is also evidence that phosphate depletion impairs intracellular glucose metabolism with a resultant increase in intracellular osmolarity as measured by increased red cell volume and in some cases associated with haemolytic anaemia (Jacob and Amsden, 1971). Paradoxically, the impairment of glucose metabolism may have contributed in part to the reports of an association of hypophosphataemia with the use of insulin (Wright, 1973; Allison, 1976).

The occurrence of hypophosphataemia when the major source of intravenous energy has been derived from carbohydrate, especially when concomitant insulin is used, has been attributed to the phosphate accompanying the entry of glucose into the cells and subsequent phosphorylation processes. The present observations have confirmed an earlier report that such depletion may occur when the major source of energy is a fat emulsion (Intralipid) even though this preparation contains phosphorus as phospholipids (Baum and Aynsley-Green, 1975). With the advent of the modern crystalline amino acid solutions, many of which do not contain phosphate where the casein hydrolysates do (Table 2) and where glucose/ insulin regimes may be used for energy provision, then the risk of hypophosphataemia is considerable.

Although hypokalaemia has often been associated with hypophosphataemia this was not uniformly seen in our patients. Like potassium and magnesium, phosphate is mainly an intracellular ion and factors causing a shift of any one of these will affect the others. When hypokalaemia accompanies hypophosphataemia it has been postulated that excessive loss of phosphate via the urine is the result of the hypokalaemic effect on renal tubular function (Betro and Pain, 1972). This is unlikely, because when a patient becomes anabolic a considerable shift of potassium into the intracellular space will occur. At least 5-6 mmol of potassium are required for the effective anabolism of each gramme of nitrogen provided (Frost and Smith, 1953). Case 3 exemplifies the association of hypophosphataemia with hypokalaemic alkalosis. A shift of phosphates may occur into red cells in association with a buffering of extracellular alkalosis. This would not necessarily militate against a low red cell 2,3-DPG level, however, as high levels of intracellular phosphate may also inhibit the normal metabolic pathways.

Patients in negative nitrogen balance following starvation or injury have increased urinary losses of phosphate but maintain normal serum inorganic phosphate levels (Cuthbertson, 1932). Thus, previously malnourished patients receiving intravenous nutrition are particular candidates for hypophosphataemia. Since, as their metabolism is shifted towards anabolism with the formation of phosphorylated intermediary compounds and the formation of ATP together with an overall increase in cell protoplasm, extracellular phosphorus depletion will become highlighted. In such cases the finding of a low red cell phosphate may indicate a differential shift of emphasis to anabolic processes for example in muscle and hepatic cells (Miller et al., 1952) as opposed to erythrocytes which have a metabolism independent of insulin.

Two of the present patients developed hypophosphataemia even though they had acute renal failure and required haemodialysis. Previous reports have shown that essential amino acid therapy reduces serum phosphorus levels in acute renal failure (Abel, Abbott and Fischer, 1972) and in 
chronic renal failure (Heidland and Kult, 1975) by presumed incorporation of inorganic phosphorus into intracellular protein synthesis. Coupled with this it must be appreciated that dialysis losses (Fig. 1) will accentuate any tendency to a hypophosphataemia in such cases.

Possible sources of phosphorus for parenteral nutrition are protein hydrolysates, fat emulsions and inorganic phosphate solutions. The amounts derived from these sources are shown in Table 2 . Intravenous fat emulsions in the form of Intralipid (soya oil emulsion) $10 \%$ and $20 \%$ supply $15 \mathrm{mmol}$ of phosphorus per litre and when $2 \mathrm{~g}$ of fat are given per $\mathrm{kg}$ body-weight this will provide 0.3 and 0.15 $\mathrm{mmol} / \mathrm{kg}$ of phosphate respectively (Wretlind, 1974). The present authors' studies throw some doubt as to the most useful source of phosphorus to use during total parenteral nutrition. It has hitherto been assumed that the phosphate content of protein hydrolysates, e.g. Aminosol $10 \%$, is readily metabolically available. It is perhaps interesting that in the U.K., with the more recent shift of emphasis towards using synthetic crystalline amino acid preparations, that hypophosphataemia is now becoming a problem. The observations here, together with a previous report (Baum and AynsleyGreen, 1975) cast doubt as to whether 'Intralipid' phospholipid phosphate is metabolically available. It would appear that an actual supplement of neutral phosphate should be included during an intravenous nutritional regime to prevent the occurrence of hypophosphataemia. The time of onset of hypophosphataemia varies enormously, sometimes very early, other times after a considerable lag. As seen in Fig. 3 hypophosphataemia may recur even when an earlier episode has been corrected. The time duration effect may be related to the time taken to change from a catabolic to an anabolic state. It must be emphasized there is no direct correlation between the serum phosphate levels and the onset of symptoms, particularly with respect to central nervous system symptoms. The recommended daily allowance of phosphorus of $0.15 \mathrm{mmol} / \mathrm{kg}$ may well be acceptable if phosphorus is provided as a neutral phosphate intravenous supplement and also to a patient who has not been severely catabolic. It would appear that the same may not be true for the type of catabolic patients treated here and with the phosphate sources used.

Whilst it may be difficult to be dogmatic about the absolute amounts of phosphate required during intravenous regimes it it equally clear that careful monitoring of serum phosphate levels is mandatory during intravenous nutrition. Other studies have suggested that the optimum daily intravenous nitrogen and energy intakes for adults are $0 \cdot 22-0 \cdot 24$ $\mathrm{g}$ and $45 \mathrm{kcal} / \mathrm{kg}$ body-weight (Hartley and Lee,
1976). Using the recommended daily allowance of phosphorus of $0.15 \mathrm{mmol} / \mathrm{kg}$, the nitrogen : phosphorus and energy : phosphorus ratios would be $1.46-1.6$ and 300 , respectively. The mean nitrogen : phosphorus and energy : phosphorus ratios obtained in the patients reported here were 1.16 (range 0.22 $1 \cdot 84$ ) and 174 (range 70.6-441). As a result of these observations, the authors recommend that $0.5-0.75$ mmol of phosphorus $/ \mathrm{kg}$ body-weight be given to acutely ill adults. Based on the optimum nitrogen and energy requirements referred to above, this would provide nitrogen $(0 \cdot 22-0 \cdot 24)$ : phosphorus $(0.5 \mathrm{mmol})$ ratios of $0.44-0.48$ or nitrogen : phosphorus $(0.75 \mathrm{mmol})$ ratios of $0.29-0.32$ and energy : phosphorus ratios of 90-60.

For infants the suggested intravenous nitrogen, energy and phosphorus intakes are $100 \mathrm{kcal}, 0.4 \mathrm{~g}$ and $1.3 \mathrm{mmol} / \mathrm{kg}$ for $24 \mathrm{hr}$. Thus nitrogen : phosphorus and energy : phosphorus ratios of 1.3 and 77 respectively are recommended. Based on these figures sixty-three patients were treated with total intravenous nutrition for periods varying between 20 days and 9 months without hypophosphataemia occurring (Ricour et al., 1975).

Although it must be assumed, in all the patients with hypophosphataemia in this study, that a considerable store of phosphorus is contained in the bone depots, it is equally clear that this is not readily metabolically available. Carpo-pedal spasm occurred in one of the cases treated with neutral phosphate infusion and this could be related to the rate of administration. It is unlikely that the provision of extra phosphorus of the levels suggested can lead to adverse metabolic complications provided one is aware of the implications with regard to calcium and magnesium homeostasis. However, it must be appreciated that the phosphate solutions normally used contain additional potassium and sodium depending on their formulation (see Table 1). Despite the uncertainty as to the exact mechanisms involved in the hypophosphataemia which can occur with intravenous nutrition, the authors feel there is sufficient evidence that it should be avoided and that the use of Intralipid as a major energy source does not provide sufficient phosphorus for some patients.

\section{Acknowledgments}

We wish to express our thanks to the surgeons in the Portsmouth and Bristol Groups of Hospitals who referred the patients described for metabolic management.

\section{References}

Abel, R.M., Abbott, W.M. \& Fischer, J.E. (1972) Intravenous essential L-amino acids and hypertonic dextrose in patients with acute renal failure. Effects on serum potassium, phosphate and magnesium. American Journal of Surgery, 123, 632. 
Allison, S.T. (1976) Personal communication.

Baum, J.D. \& AynSLEY-GreEN, A. (1975) Intravenous feeding in children. Experience with metabolic monitoring. Clinical Trials Journal, 12, 114.

Betro, M.G. \& PAIN, R.W. (1972) Hypophosphataemia and hyperphosphataemia in a hospital population. British Medical Journal, 1, 273.

Craddock, P.R., Yawata, Y., Van Santen, L., GieberSTADT, S., Silvis, S. \& JACOB, H.S. (1974) Acquired phagocytic dysfunction. A complication of the hypophosphatemia of parenteral hyperalimentation. New England Journal of Medicine, 290, 1403.

Cuthrertson, D.P. (1932) Observations on the disturbance of metabolism produced by injury to the limbs. Quarterly Journal of Medicine, 25, 233.

Frost, P.M. \& SMith, J.C. (1953) Influence of potassium salts on efficiency of parenteral protein alimentation in the surgical patient. Metabolism, 2, 529.

Garner, G.B., Huebner, P.F. \& O'Dell, B.L. (1967) Dietary sufferers and some salmonellosis in guinea-pigs. Federation Proceedings, 26, 799.

HaRTley, T.F. \& LeE, H.A. (1976) Investigations into the optimum nitrogen and caloric requirements and comparative nutritive value of three intravenous amino acid solutions in the post-operative period. Nutrition and Metabolism, 19, 201.

Heidland, A. \& Kult, J. (1975) Long-term effects of essential amino acids supplementation in patients on regular dialysis treatment. Journal of Clinical Nephrology, 3, 234.

JACOB, H.S. \& AMSDEN, T. (1971) Acute hemolytic anemia with rigid red cells in hypophosphatemia. New England Journal of Medicine, 285, 1446.

LeE, H.A. \& HARTley, T.F. (1975) A method of determining daily nitrogen requirements. Postgraduate Medical Journal, 51, 441 .
MaenPaA, P.H., Rairo, K.O. \& KeKomaki, M.P. (1968) Liver adenine nucleotides: fructose-induced depletion and its effect on protein synthesis. Science, 161, 1253.

Miller, M., Drucker, W.R., OWens, J.E., Craig, J.W. \& WOODWARD, H. (1952) Metabolism of intravenous fructose and glucose in normal and diabetic subjects. Journal of Clinical Investigation, 31, 115.

Prins, J.G., Schrijner, H. \& Staghouwer, J.H. (1973) Hyperalimentation, hypophosphataemia and coma. Lancet, i, 1253.

Recommended Dietary Allowances (1968) National Academy of Sciences Washington, DC. 7th Edn.

Ricour, C., Millot, M. \& Balsan, S. (1975) Phosphorus depletion in children on long-term parenteral nutrition. Acta paediatrica scandinavica, 64, 385.

Riedler, G.F. \& Scheitlin, W.A. (1969) Hypophosphataemia in septicaemia : higher incidence in Gram-negative than in Gram-positive injections. British Medical Journal, 1, 753.

Sheldon, G.F. \& Gryzb, S. (1975) Phosphate depletion and repletion. Annals of Surgery, 182, 683.

Silvis, S.E. \& Paragas, P.D.'(1972) Paraesthesiae, weakness, seizures and hypophosphatemia in patients receiving hyperalimentation. Gastroenterology, 62, 513.

Travis, S.F., Sugerman, H.J., Ruberg, R.L., Dudrick, S.J., Delivoria-Papadopoulos, M., Miller, L.D. \& Oski, F.A. (1971) Alterations of red cell glycolytic intermediates and oxygen transport as a consequence of hypophosphatemia in patients receiving intravenous hyperalimentation. New England Journal of Medicine, 285, 763.

Woods, H.F. \& AlberTI, K.G.M.M. (1972) Dangers of intravenous fructose. Lancet, ii, 1354.

Wretlind, A. (1974) In: Parenteral Nutrition in Acute Metabolic Illness (Ed. by H. A. Lee), p. 365. Academic Press Ltd, London.

Wrighr, P.D. (1973) Intravenous feedings. (Correspondence.) Lancet, ii, 1335. 